\title{
Perlawanan Positif Komunitas Punk Endank Soekamti
}

\author{
Namira Choirani Fajri \\ Fakultas IImu Budaya Universitas Airlangga \\ Email: namirachoirani22@gmail.com
}

Naskah diterima 25 Maret 2020, Revisi 10 April 2020, Terbit 19 April 2020

DOI: doi.org/10.21107/pamator.v13i1.6951

\begin{abstract}
Abstrak
Stereotip buruk masih kerap kali membayangi kelompok punk Indonesia. Padahal, kelompok punk Indonesia tidak sepenuhnya menyadur sikap perlawanan dan antikemapanan dari negara asalnya, Inggris. Oleh karena itu, penelitian mengenai karakteristik punk di Indonesia perlu dilakukan agar tidak terjadi generalisasi pada kelompok tersebut. Tujuan penelitian ini adalah meninjau spesifikasi karakter punk yang berkembang di Indonesia saat ini. Penelitian ini menggunakan metode kualitatif. Pada penelitian ini, studi kasus yang digunakan adalah grup musik Endank Soekamti sebagai salah satu grup musik pop-punk di Indonesia. Data penelitian diperoleh melalui observasi aktivitas dan praktik grup musik Endank Soekamti. Hasil penelitian menunjukkan bahwa aktivitas Endank Soekamti menunjukkan semangat perlawanan, tetapi tidak sepenuhnya memenuhi kaidah punk sebagai kelompok antikemapanan. Kelompok ini juga berkontribusi untuk pendidikan anak bangsa. Dari penelitian ini, diperoleh hasil bahwa Endank Soekamti sebagai salah satu kelompok punk Indonesia mewujudkan semangat perlawanannya melalui hal yang positif dan tidak menggunakan jalur kekerasan.
\end{abstract}

Kata Kunci : Endank Soekamti, grup musik, punk, sub-kultur

\begin{abstract}
Bad stereotypes still often overshadow Indonesian punk groups. In fact, Indonesian punk groups did not fully adapt the resistance and anti-establishment attitude of their home country, England. Therefore, research on the characteristics of punk in Indonesia needs to be done so that there is no generalization in the group. The purpose of this study is to review the specifications of punk characters that are developing in Indonesia today. This study uses a qualitative method. In this research, the case study used is the Endank Soekamti music group as one of the pop-punk music groups in Indonesia. The research data were obtained through observing the activities and practices of Endank Soekamti music group. The results showed that Endank Soekamti's activity showed a spirit of resistance, but did not fully fulfill the punk rules as an antiestablishment group. This group also contributes to the education of the nation's children. From this study, it was obtained that Endank Soekamti as one of the Indonesian punk groups embodied the spirit of resistance through positive things and did not use violence.
\end{abstract}

Keywords : Endank Soekamti, music group, punk, sub-culture

\section{PENDAHULUAN}

Punk di Indonesia tidak lepas dari stereotip negatif dan kerapkali dikaitkan dengan perilaku tidak terpuji. Hadirnya stereotip ini berkaitan dengan napas utama punk yang membawa semangat perlawanan (Hebdige, 1999). Bentuk perlawanan dari kelompok punk ini tidak terlepeas dari counter-culture didasari oleh beberapa unsur utama, yaitu musik, fesyen, komunitas (Al Ramadhan, 2016).

Counter-culture yang diusung kelompok punk ini menjadikannya kerapkali menerima perlakuan diskriminatif. Pada Juni 2016, organisasi Nadhlatul Ulama, salah satu organisasi Islam di Indonesia, cabang Demak melarang konser reggae dan punk karena dianggap 'berpakaian aneh' dan 'di luar sepanjang malam' (Handayani, 2016). Adanya larangan ini menunjukkan bahwa generalisasi dan cap pada kelompok punk masih berkembang di Indonesia. Pernyataan tersebut diperkuat oleh penelitian yang dilakukan Rokib dan Sodiq (2017). Dalam penelitiannya, mereka menemukan data bahwa sekalipun anggota kelompok punk telah menunjukkan identitas religuisitasnya, tetapi tato yang menjadi 
identitas punk mereka masih menjadi masalah menurut pandangan masyarakat. Meskipun telah menerima pendapat dari beberapa ulama bahwa tato adalah masalah sampingan dalam Islam, kelompok punk masih dipandang kotor karena berlandaskan tato yang mereka miliki.

Di sisi lain, penelitian sebelumnya yang dilakukan oleh Utama dan Hujatnika (2013) mengungkapkan bahwa punk di Indonesia telah seiring waktu berubah menjadi suatu sub-kultur yang begitu diminati oleh anak muda. Minat tersebut tumbuh seiring ketidakmampuan solusi dari isu-isu ideologi, politis, serta norma untuk dituntaskan, sehingga kondisi memberontak yang awalnya ditawarkan oleh subkultur punk dapat menjadi jawaban bagi masyarakat. Namun, seiring berjalannya waktu punk mengalami redefinisi dari subkultur punk ini ditunjang kuat oleh perbaurannya dengan kondisikondisi lokal masyarakat Indonesia, yang lagi-lagi menghilangkan citra awal punk yang rusuh dan pemberontak kini bahkan dapat bersifat lucu dan kata punk itu tadi hanyalah sekadar tampilan sesorang belaka (Utama and Hujatnika, 2013). Penelitian sebelumnya tersebut menunjukkan bahwa citra kelompok punk tidak lagi dapat digeneralisir. Hal tersebut terlihat dari adanya kelompok punk yang tidak lagi mengikuti pakem punk dari Inggris.

Di Indonesia, salah satu kelompok punk yang memiliki banyak pengikut adalah Endank Soekamti. Banyaknya pengikut Endank Soekamti ini terlihat dari album fisik yang terjual 5000 unit (Barus, 2020). Jumlah tersebut tergolong tinggi tengah era digital saat ini. Selain itu, berdasarkan penelitian Prasetyo (2011) sejumlah 5000 orang yang mengaku sebagai kamtis family (penggemar Endank Soekamti). Band yang beraliran pop-punk ini merupakan band musik asal Yogyakarta yang bergerak di label buatan mereka sediri. Kelompok ini melakukan perlawanan dengan aksi langsung pada perubahan, tidak sekadar dari lirik lagu yang mereka buat.

Penelitian ini memiliki fokus pada karakteristik punk di Indonesia yang ditunjukkan melalui aktivitas grup musik Endank Soekamti. Telaah mengenai karakteristik punk di Indonesia ini perlu dilakukan mengingat generalisasi terhadap kelompok punk masih terjadi. Apabila penelitian sebelumnya menelaah tentang negosiasi punk muslim di Indonesia, penelitian ini akan menggali tentang kontribusi kelompok musik punk, Endank Soekamti, yang mengandung semangat perlawanan, tetapi tidak menempuh jalur kasar. Hadirnya penelitian ini selanjutnya dapat berimplikasi pada pengetahuan agar generalisasi kelompok punk tidak lagi terjadi di Indonesia.

Menurut Hebdige (1999), gaya adalah praktik signifikasi yang pada kasus subkultur hura-hura menjadi tampilan penuh rekayasa. Melalaui signifikasi perbedaan gaya membentuk identitas kelompok. Punk bukan hanya merupakan respons atas krisis kemunduran yang termanifestasi dalam pengangguran, kemiskinan, dan berubahnya standar moral. Gaya punk adalah ekspresi kemarahan dan frustasi yang melekat pada satu bahasa yang umumnya ada namun sekarang dimaknai sebagai gejala dari sekumpulan masalah kontemporer (Schoggen dan Barker, 1974). Proses perlawanan menurut Hebdige dimulai dengan kejahatan melawan tertib alami, meskipun dalam hal ini penyimpangannya boleh akan tampak sangat enteng dan diakhiri dengan konstruksi gaya dengan gestur menyimpang atau menghina, namun hal ini merupakan sinyal penolakan (Hebdige, 1999).

Endank Soekamti memang memiliki penampilan yang identik dengan kelompok punk, namun Endank Soekamti memiliki perlawanan yang berbeda dari punk lainnya. Punk identik dengan anti-kemapanan, tidak peduli terhadap pendidikan, dan fokus pada orang di dalam komunitasnya, namun lain hal dengan Endank Soekamti yang mengungkapkan perlawanan lewat gerakan peduli pendidikan pada orang-orang di daerah yang kerap terabaikan. Perlawanan Endank Soekamti dapat ditinjau dari teori yang dikemukakan Hebdige bahwa subkultur bukan hanya sebuah gaya melainkan juga simbol perlawanan.

Teori yang dikemukakan Hebdige tidak sepenuhnya mewakili subkultur Endank Soekamti, oleh karena itu teori subkultur yang dikemukakan oleh Sara Thornton juga digunakan dalam penelitian ini. Subkultur Endank Soekamti merupakan subkultur 
yang tidak hanya merupakan gaya tapi juga mengandung unsur perlawanan. Endank Soekamti tidak ingin mendeklarasikan diri sebagai punk, tetapi juga tidak melarang untuk disebut punk. Endank Soekamti memiliki gaya (style) yang ingin ditunjukkan. Sara Thornton mengungkapkan bahwa saat ini subkultur tidak hanya ditujukan sebagai media perlawanan, tetapi gaya yang dimilikinya juga dapat digunakan sebagai identitas suatu kelompok (Thornton, 1994).

\section{METODOLOGI}

Penelitian ini menggunakan metode deskriptif kualitatif untuk mencari makna objek yang dikaji (Stokes, 2006; Blevins dan Holt, 2009). Data penelitian diperoleh dari media sosial Endank Soekamti, saluran youtube Endank Soekamti, serta skrip wawancara Endank Soekamti. Selain itu, data primer tersebut dilengkapi dengan data sekunder yang diperoleh dari buku-buku referensi dan berita pada media massa mengenai Endank Soekamti, punk, dan indie. Dalam penelitian ini teknik pengumpulan data yang dilakukan adalah dengan cara observasi melakukan pengamatan secara detail terhadap objek kajian yang diteliti dalam website resmi, saluran youtube resmi, akun media sosial resmi, dan wawancara yang pernah dilakukan personil Endank Soekamti. Pertama pemilihan data fokus pada gaya mereka sebagai subkultur Endank Soekamti dan gerakan-gerakan yang mereka lakukan. Gerakan tersebut meliputi gebrakangebrakan yang mereka usung dan menjadi simbol perlawanan.

\section{HASIL DAN PEMBAHASAN}

\section{Musik Endank Soekamti}

Endank Soekamti merupakan band yang dapat dikatakan berbeda karena telah mengambil langkah berani yaitu keluar dari major label. Di Major label, Endank Soekamti tidak dapat menuangkan ide sesuai dengan keinginannya. Pada akhirnya Endank Soekamti membangun kariernya sendiri melalui jalur indie. Pertama, Endank Soekamti mendirikan perusahaan rekaman sendiri yang bernama Euforia Records, Ialu selanjutnya dibentuk Euforia Audio Visual yang menggarap film, Euforia Pustaka yang menggarap buku, dan Euforia Digital sebagai web developer. Seluruh perusahaan yang mereka buat ini sebelumnya merupakan perusahaan yang ditujukan untuk kepentingan Endank Soekamti saja, tetapi pada saat ini perusahaan-perusahaan ini pun telah menggarap proyek-proyek lain. $\mathrm{Hal}$ ini menunjukkan bahwa Endank Soekamti tak lagi melihat kepentingan mereka saja, namun juga ingin membantu band atau musisi lain dalam berkarya serta menjadikan keahlian mereka untuk lahan bisnis.

Istilah "indie" merupakan kependekan dari independensi yang awal kemunculannya merupakan identifikasi terhadap subkultur pop underground di Ingrris yang berevolusi. Pemendekan kata independent ini mengandung definisi kontekstual indie yang menjadi basis pergerakan subkultural. Indie merupakan counter-culture terhadap mainstream. Indie menjadi representasi anak-anak kutu buku yang berkacamata tebal yang mengeksplorasi punk sesuka mereka. Namun, seperti yang dijelaskan di atas, kelamaan musik indie yang sebelumnya merupakan counter musik populer juga menjadi lahan yang dikomersilkan, di sinilah kehadiran Endank Soekamti sebagai salah satu grup yang khas datang untuk mengcounter musik indie yang mulai terkikis tujuan awalnya seiring berjalannya waktu (Tantagode, 2008).

Cita-cita Endank Soekamti di kemudian hari adalah band-band terutama lokal dapat melepaskan dari hegemoni label. Rumah produksi yang telah dirintis Endank Soekamti diharapkan dapat membantu band-band tersebut sehingga tidak harus terpaku pada label major. Band lokal dapat terus berkiprah dan sukses di tanahnya sendiri karena pada dasarnya mereka adalah aset daerah. Selain itu, band-band ini juga dapat berkarya sesuai keinginan mereka bukan keinginan label ataupun pasar. Di sinilah Endank Soekamti mengedukasi band lain tentang pentingnya hak untuk bebas berkarya.

Langkah lain yang diambil Endank Soekamti dalam bermusik adalah di saat semua musisi beralih ke digital, Endank Soekamti justru masih bertahan untuk memasarkan album fisiknya. Menurut mereka pada wawancara dengan Media Indonesia pada 2 April 2016, sudah tidak zamannya lagi untuk memerangi pembajak. 
Saat ini, yang harus dipentingkan adalah berdamai dan memberi yang terbaik untuk orang-orang yang mendukung mereka. Hal ini merupakan gerakan lain dari Endank Soekamti yang ingin menampilkan sisi bahwa mereka merupakan band yang antimainstream. Langkah yang dilakukan Endank Soekamti menunjukkan bahwa cara untuk membesarkan komunitas bukan lah lewat penurunan kualitas bermusik mereka, namun lewat cara-cara seperti berkolaborasi dengan musisi lain. Endank Soekamti kolaborasi dengan musisi ternama Indonesia, seperti Slank, Coboy Junior, Cherrybelle pada album Kolaborasoe dengan tujuan agar pendengar musisimusisi lain juga mendengarkan Endank Soekamti. Hal ini merupakan strategi Endank Soekamti untuk mempromosikan bandnya, namun bukan melalui penurunan kualitas bermusik mereka. Musisi yang dipilih pun tidak selalu sejalan dengan musik Endank Soekamti yang beraliran pop-punk sehingga dapat memperluas penikmat Endank Soekamti.

Upaya lain yang dilakukan Endank Soekamti untuk memperkenalkan bandnya adalah melalui youtube channel. Pada tahun 2006, sebelum youtube dan vlog meledak di Indonesia, Endank Soekamti telah mempromosikan bandnya lewat media ini. Endank Soekamti pada awalnya selalu mengunggah video tentang keseharian mereka di youtube channel. Hal ini dilakukan karena mereka membutuhkan "infotaiment" sendiri sehingga digunakanlah media youtube. Endank Soekamti merupakan band yang tidak menetap di ibu kota sehingga youtube dianggap merupakan media yang tepat untuk media promosi dan mendekatkan diri dengan fans. Jika dahulu fans hanya mengetahui karya-karya Endank Soekamti, youtube channel membuat fans tahu tentang proses kreatif Endank Soekamti. Usaha mereka pun terbukti berhasil karena pada launching album ke-7 mereka tahun 2016 lalu, akun yang ingin melihat acara tersebut mencapai 63.000. Jumlah tersebut jauh melebihi ekspetasi. Fenomena ini menandai keberhasilan Endank Soekamti sebagai 'band lokal' di luar label major yang berhasil memperoleh perhatian dari puluhan ribu orang.
Endank Soekamti dan Gerakan Pendidikan

Kelompok Endank Soekamti memiliki strategi khusus untuk berkontribusi pada pendidikan di Indonesia. Strategi yang dilakukan adalah dengan memanfaatkan hasil penjualan produk yang dijual oleh pihak Endank Soekamti. Harga yang dicantumkan pada produk memang terbilang tinggi, misalnya saja box set album yang mencapai harga 650 ribu rupiah. Dari tingginya harga yang dipasang, sudah ditentukan oleh pihak Endank Soekamti bahwa harga tersebut termasuk sumbangan dari pembeli (kebanyakan Kamtis Family, penggemar Endank Soekamti) untuk Diary of Erix Soekamti (DOES) University. Strategi tersebut sangat berhasil hingga terkumpul dana sebesar 300 juta rupiah sebagai modal awal berdirinya DOES University pada 16 Desember 2015.

Pada masa awal berdirinya DOES University terdapat sepuluh murid yang belajar pada bidang animasi. Bidang ini menjadi program pertama DOES University karena secara kebetulan Endank Soekamti sedang bergelut pada bidang tersebut. Pada tahun selanjutnya kapasitas murid bertambah menjadi 40 orang. Dalam seleksi masuk, Erix Soekamti menyeleksi langsung karena tujuan DOES University adalah untuk memberikan wadah bagi yang mau belajar dan menyukai yang dipelajari dalam hal ini animasi. Memang untuk sementara ini baru bidang animasi yang diajarkan, namun DOES University juga berencana membuka semua bidang yang dibutuhkan.

Sistem pembelajaran yang diberlakukan DOES University bisa dikatakan berbeda dengan sistem pembelajaran yang ada di Indonesia. Murid yang belajar di DOES University membayar semua fasilitas yang diberikan dengan cara mengabdi dan berkarya selama setahun. Jangka waktu belajar selama setahun, kemudian dilanjutkan dengan menyalurkan pengetahuan yang telah didapat kepada generasi selanjutnya. Jadi, murid dikarantina selama dua tahun, setahun untuk belajar dan setahun lagi untuk mengajar. Setelah dua tahun tersebut, DOES University masih memberikan fasilitas berupa beberapa pekerjaan maupun kebebasan untuk mendirikan studio animasi sendiri. Tanggung jawab DOES University sampai murid mendapatkan pekerjaan. 
Pergerakan yang dilakukan Endank Soekamti untuk membuat DOES University merupakan sebuah terobosan baru dan efektif dalam dunia pendidikan di Indonesia. Selain itu munculnya DOES University juga merupakan sebuah kritik terhadap pendidikan di Indonesia yang tidak jauh berbeda dengan kritik Ki Hadjar Dewantara kepada pendidikan yang dibawa oleh Belanda pada saat itu. Baik Endank Soekamti maupun Ki Hadjar Dewantara mengkritik bahwa sistem pendidikan yang digunakan di Indonesia yang meniru sistem pendidikan Barat yang tidak sesuai jika diterapkan di Indonesia (Dewantara, 1977).

Sama dengan Ki Hajar Dewantara, DOES juga bertujuan untuk meningkatkan pengetahuan peserta didik terhadap bidang yang diminatinya. Peserta didik didorong untuk mengasah pemahaman tentang hal yang diketahuinya serta meningkatkan kemampuan di bidang tertentu. Sistem ini secara tidak langsung merupakan bentuk perlawanan terhadap sistem pendidikan Barat yang dibawa ke Indonesia pada saat itu karena sistem tersebut dinilai tidak tepat diterapkan di Indonesia.

\section{Fashion}

Fashion punk pada umumnya adalah rambut mohawk, feather cut, sepatu boots, rantai dan spike, jaket kulit, jeans ketat, dan baju lusuh (Putri, 2011). Hal lain digunakan oleh Endank Soekamti. Band punk ini tidak selalu menggunakan pakaian berwarna hitam. Vokalis band, Erix Soekamti, kerap menggunakan kacamata hitam. Rambut personil Endank Soekamti punk tidak mohawk bahkan klimis. Erix Soekamti menggunakan anting besar khas punk, namun tindik yang dimilikinya diakui sebagai fashion saja yang memang menjadi tren saat dia muda. Gayanya yang khas dengan gigi perak diungkapkan sebagai fashion yang digunakan untuk menjadi identitas diri yang membedakan dengan band lain. Gigi perak menurut Erix (2014) bukan budaya barat karena nenek pada zaman dahulu pun kerap menggunakan gigi emas, oleh karena itu gigi perak yang digunakannya dianggap sebagai bentuk pelestarian terhadap budaya Indonesia. Sara Thornton mengungkapkan bahwa di era post-modern ini tidak semua gaya digunakan sebagai media perlawanan (Thornton, 1994; Moore, 2005). Hal ini terjadi pula pada subkultur Endank Soekamti yang menjadikan kelompok ini memiliki gaya atau ciri khas tersendiri.

\section{Punk Endank Soekamti}

Semboyan yang dianut oleh kaum punk pada umumnya adalah "Do It Yourself", namun hal berbeda diungkapkan oleh Endank Soekamti yaitu "Do It Together". Perbedaan semboyan ini menunjukkan bahwa Endank Soekamti ingin menunjukkan identitas punk yang berbeda dari anggapan sebelumnya. Punk yang diadaptasi dari budaya barat kerap kali mengedepankan independensi kelompok mereka. Kelompok punk biasanya menjual barang-barang yang mereka produksi sendiri dengan tujuan untuk melawan pemuja merk. Harga produk yang mereka produksi sendiri tersebut dapat dikatakan sangat terjangkau, berbeda dengan kaos official Endank Soekamti yang dijual dengan harga paling murah 150 ribu rupiah. Atribut official Endank Soekamti lain, seperti jaket dijual dengan harga 500 ribu rupiah, kacamat kayu seharga 1 juta rupiah, dan cincin seharga 3,5 juta rupiah.

Kehadiran punk sebenarnya tidak terlepas dari perlawanan pada masyarakat yang mengkonsumsi produk - produk yang ditawarkan oleh industri dan berada diluar kontrol hidupnya. Masyarakat modern dan budaya modern membentuk dirinya sendiri menjadi masyarakat konsumen dan budaya konsumtif. Kelompok punk menolak 'pasar' yang mereka anggap sebagai pusat budaya konsumtif karena mereka menolak adanya budaya konsumtif tersebut (Pandu Rahadya Utama and Hujatnika, 2013). Meninjau fakta bahwa Endank Soekamti tidak menjual atributnya dengan murah, terlihat bahwa kelompok ini tidak mengikuti pandangan punk yang telah dipaparkan sebelumnya. Namun, di sisi lain, Endank Soekamti juga mempergunakan hasil penjualannya untuk kegiatan sosial.

Genre musik Endank Soekamti adalah pop-punk, namun pada wawancara yang dilakukan Metro TV News pada 17 November 2014 mereka mengungkapkan bahwa genre yang mereka anut tidak direncanakan. Endank Soekamti merupakan band yang memilih untuk memainkan musik yang ingin mereka mainkan. Band punk lain, seperti Marjinal misalnya, memainkan musiknya dengan lirik yang kritis terhadap 
politik, lingkungan hidup, sosial, dan ekonomi. Berbeda dengan Endank Soekamti yang memang masih memiliki ciri khas musik punk dalam lagu-lagunya karena liriknya sederhana, kadang kasar, bertempo cepat dan menghentak, namun mereka tidak menyentuh aspek politik dan ekonomi dalam lirik lagunya. Lirik lagu Endank Soekamti identik dengan gaya jenaka khas Jawa karena mereka berasal dari Jogjakarta. Selain itu, Endank Soekamti (2014) mengungkapkan bahwa tidak ingin mengikuti tren karena dianggap basi, hal terpenting bagi mereka adalah mengerti yang mereka mainkan bukan sekadar untuk diperjual-belikan. Bagi Endank Soekamti, kritik mereka terhadap pemerintah tidak diungkapkan lewat lirik yang mengandung kemarahan, melainkan melalui aksi kreatif yang dapat memancing kreator-kreator muda untuk terus berkarya.

Dari hasil yang telah dipaparkan di atas, tampak bahwa Endank Soekamti tidak sepenuhnya menganut pakem punk dari Inggris. Punk Endank Soekamti memiliki karakteristik lain, yaitu mengusung semboyan do it together yang artinya kelompok ini tidak hanya peduli pada komunitasnya saja, melainkan juga ingin berkontribusi pada lingkungan yang lebih besar. Selain itu, Endank Soekamti juga tidak menampilkan kekerasan baik dalam karyanya maupun aksinya. Perlawanan yang ditunjukkan Endank Soekamti adalah aksi nyata dan kontribusi pada orang lain.

\section{KESIMPULAN}

Punk di Indonesia tidak dapat digeneralisasikan. Masing-masing kelompok punk memiliki karakteristik dan caranya masing-masing untuk menyampaikan semangat perlawanannya. Pada kelompok punk Endank Soekamti, perlawanan tidak disampaikan melalui kekerasan, melainkan lewat aksi nyata dan kontribusi. Adanya kelompok punk Endank Soekamti dan aktivitasnya menunjukkan spektrum perlawanan lain dalam subkultur punk. Oleh karena itu, penilaian terhadap kelompok punk tidak dapat dilakukan melalui penampilan fisiknya saja, melainkan juga aksi dan kontribusinya di masyarakat.

\section{DAFTAR PUSTAKA}

Al Ramadhan, M.F. 2016. Punks Not Dead: Kajian Bentukan Baru Budaya Punk di Indonesia. MAKNA: Jurnal Kajian Komunikasi, Bahasa, Dan Budaya, 1(1), 54-63 pp.

Barus, A.K. 2020. Ikuti Jejak Endank Soekamti Netral Gairahkan Penjualan Album Fisik. Retrieved from Jawa Pos website: https://www.jawapos.com/entertainm ent/music-movie/17/01/2019/ikutijejak-endank-soekamti-ntrlgairahkan-penjualan-album-fisik/

Blevins, K.R., \& Holt, T.J. 2009. Examining the virtual subculture of Johns. Journal of Contemporary Ethnography. Vol 38 No 5. 619-648 pp.

Dewantara, K.H. 1977. Bagian Pertama Pendidikan. Yogyakarta: PerCetakan Taman Siswa.

Handayani, E. V. 2016. Muslim Punks In Mohawks Attacked: Punks In Indonesia are Persecuted But Still Manage To Maintain A Culture Which Stands Up For Difference. Index on Censorship. Vol 45. No 4. 39-43 pp.

Hebdige, D. (1999). Asal-Usul \& Ideologi Subkultur Punk. Penerbit : Buku Baik.

Moore, R. 2005. Alternative to What? Subcultural Capital and The Commercialization of A Music Scene. Deviant Behavior. Vol 26. No 3. 229$252 \mathrm{pp}$.

Utama, P.R \& Hujatnika, A. 2013. Mencari Punk Indonesia. Jurnal Tingkat Sarjana Bidang Seni Rupa.

Prasetyo, W. 2011. Pengaruh Citra Band Endank Soekamti terhadap Loyalitas Penggemar di Yogyakarta. Universitas Atma Jaya Yogyakarta.

Putri, A.S. 2011. Fashion Punk Dan Identitas Remaja : Analisis Semiologi Terhadap Simbol-Simbol Visual Dalam Fashion Komunitas Punk Modis Solo Grand Mall (SGM) Di Surakarta. 
Rokib, M., \& Sodiq, S. 2017. Moslems with tattoos: The Punk Muslim Community in Indonesia. Al-Jami'ah. Vol 55. No 1. 47-70 pp.

Schoggen, P., \& Barker, R.G. 1974. The Ecological Psychology of Adolescents in an American and an English Town. In The Adolescent and His Environment. Vol 1. 12-23 pp. Karger Publishers.

Stokes, J. 2006. How To Do Media And Cultural Studies: Panduan Untuk Melaksanakan Penelitian Dalam Kajian Media dan Budaya. Bentang Pustaka.

Tantagode, J. 2008. Musik Underground Indonesia Revolusi Indie Label. Yogyakarta: Harmoni.

Thornton, S. 1994. Moral Panic The Media And British Rave Culture.

\section{Sumber Daring}

Wawancara Metro TV News pada 17 November 2014
http://m.metrotvnews.com/hiburan/indis/IKY7 jzVb-wawancara-endank-soekamtimerdeka-mandiri-dan-penuh-strategi.

Wawancara Media Indonesia pada 2 April 2016

https://www.youtube.com/watch?v=w 1QxhnO7SaY.

Erix Soekamti dalam Lentera Indonesia pada 8 Januari 2017

https://www.youtube.com/watch?v=ulzruunK Iv0\&t=330s.

Wawancara pada launching album Endank Soekamti: Salam Indonesia pada 9 September https://www.youtube.com/watch?v=i5 dIMH8jByU\&t=11s.

Youtube channel official Endank Soekamti https://www.youtube.com/user/soeka mtiofficial.

Youtube channel official Erix Soekamti https://www.youtube.com/user/ErixSo ekamti. 
2 Jurnal Pamator 